\title{
Protection of Retinal Ganglion Cells from Natural and Axotomy-Induced Cell Death in Neonatal Transgenic Mice Overexpressing bcl-2
}

\author{
Lidia Bonfanti, ${ }^{1}$ Enrica Strettoi, ${ }^{1}$ Sabrina Chierzi, ${ }^{2}$ Maria Cristina Cenni, ${ }^{1}$ Xiu-Huai Liu, ${ }^{2}$ \\ Jean-Claude Martinou, ${ }^{3}$ Lamberto Maffei, ${ }^{1,2}$ and Sylvia A. Rabacchi ${ }^{1,2}$ \\ 1/stituto di Neurofisiologia del Consiglio Nazionale delle Ricerche, 56127 Pisa, Italy, ${ }^{2}$ Scuola Normale Superiore, 56127 \\ Pisa, Italy, and ${ }^{3}$ Glaxo Institute for Molecular Biology, Geneva, Switzerland
}

Approximately half of the retinal ganglion cells (RGCs) present in the rodent retina at birth normally die during early development. Overexpression of the proto-oncogene bcl-2 recently has been shown to rescue some neuronal populations from natural cell death and from degeneration induced by axotomy of nerves within the peripheral nervous system. Here we study in vivo the role of the overexpression of bcl-2 in the natural cell death of RGCs and in the degenerative process induced in these cells by transection of the optic nerve. We find that in newborn bcl-2 transgenic mice, the number of RGCs undergoing natural cell death is considerably lower than in wild-type pups. Consistently, a vast majority $(90 \%)$ of the ganglion cells found in the retina of neonatal transgenics are maintained in adulthood, whereas only $40 \%$ survive in wild-type mice.
After transection of the optic nerve, the number of degenerating ganglion cells, determined by counting pyknotic nuclei or nuclei with fragmented DNA, is substantially reduced in transgenic mice. In wild-type animals, almost $50 \%$ of ganglion cells degenerate in the $24 \mathrm{hr}$ after the lesion, whereas almost the entire ganglion cell population survives axotomy in transgenic mice. Therefore, overexpression of bcl-2 is effective in preventing degeneration of this neuronal population, raising the possibility that ganglion cells are dependent on the endogenous expression of bcl-2 for survival. The remarkable rescue capacity of bcl-2 overexpression in these neurons makes it an interesting model for studying natural cell death and responses to injury in the CNS.

Key words: retinal ganglion cells; optic nerve; apoptosis; developmental cell death; axotomy; bcl-2
Natural cell death (or apoptosis) is a widespread phenomenon occurring during development of the nervous system; it is believed to regulate neuronal number and ensure specificity of synaptic connections (Cowan et al., 1984; Catsicas et al., 1987; Ellis et al., 1991; Oppenheim, 1991; Raff, 1992; Johnson and Deckwerth, 1993). Apoptosis also has been implicated recently in the neuronal degeneration that follows injury. For example, it takes place in retinal ganglion cells (RGCs) as a consequence of axotomy performed during development (Rabacchi et al., 1994a) or in the adult animal (Berkelaar et al., 1994; Garcia-Valenzuela et al., 1994).

Injury to the CNS often has extremely severe consequences attributable to the sparse regeneration of affected neurons. The exogenous administration of trophic factors (Carmignoto et al., 1989; Maffei et al., 1990; Mey and Thanos, 1993; Mansour-Robaey et al., 1994; Rabacchi et al., 1994b) or other substances (Thanos et al., 1993; Huxlin et al., 1995) has been used to enhance survival of RGCs after axotomy, whereas peripheral nerve grafts or antibodies neutralizing myelin-associated inhibitory molecules have been introduced to promote axonal regeneration of RGCs (Vidal-Sanz et al., 1987; Weibel et al., 1994). The outcomes of these strategies are only partially successful because of the limited neuronal

\footnotetext{
Received Jan. 16, 1996; revised April 3, 1996; accepted April 11, 1996.

This work was partially supported by the International Institute for Paraplegia, Zurich, Switzerland, Grant P24. We are grateful to Dr. K. A. Jones for critical comments on this manuscript and to Mr. A. Bertini for photographic work.

Correspondence should be addressed to Lamberto Maffei, Istituto di Neurofisiologia del Consiglio Nazionale delle Ricerche, Via S. Zeno 51, 56127 Pisa, Italy.

Copyright (C) 1996 Society for Neuroscience $0270-6474 / 96 / 164186-09 \$ 05.00 / 0$
}

survival and paucity of regenerating fibers. The rapidity of the degeneration of injured RGCs (Berkelaar et al., 1994) suggests that regeneration may be improved considerably by prolonging survival. The identification of the molecular mechanisms underlying traumatic degeneration in the CNS therefore seems crucial for the development of new approaches aimed at protecting neurons from death.

Several genes have been identified that play a key role in the positive and negative regulation of apoptosis (Oppenheim et al., 1990; Ellis et al., 1991; Osborne and Schwartz, 1994; Davies, 1995; Korsmeyer, 1995). The product of the proto-oncogene bcl-2, an intracellular membrane-associated protein, protects cells from apoptosis in vitro (Garcia et al., 1992; Allsopp et al., 1993; Mah et al., 1993). Recently, transgenic mice have been generated in which most CNS neurons overexpress the human bcl-2 gene; some of these neurons are protected from natural cell death, ischemia, and injury. In particular, in neonatal animals, facial (Dubois-Dauphin et al., 1994) and spinal motoneurons (Farlie et al., 1995), which normally die after transection of their peripheral nerves, are protected in transgenic mice. If performed in the normal adult, however, such a peripheral nerve injury does not lead to degeneration, and axonal regeneration and functional recovery occur. In contrast, axotomy performed on a central nerve usually results in massive neuronal degeneration in both developing and adult animals.

Mice overexpressing bcl-2 have enlarged optic nerves, suggesting that RGC survival during development is enhanced (Martinou et al., 1994). Here we have used bcl-2 transgenic mice to address two issues. First, we investigate whether and to what extent high levels of the Bcl-2 protein could rescue RGCs from developmen- 
Table 1. Number of ganglion cells/retina

\begin{tabular}{llc} 
& P1-2 & Adult $^{a}$ \\
\hline Wild-type & $115,000 \pm 9550$ & $45,400 \pm 4000$ \\
bcl-2 & $129,000 \pm 8200$ & $112,400 \pm 17,400$
\end{tabular}

${ }^{a}$ Number of retinal ganglion cells in the adult retina determined by counting their axons on electron micrographs of ultrathin transverse sections of optic nerves. Three nerves of wild-type mice and four nerves of bcl-2 transgenic mice were used. All of the axons that were included in $6-12 \%$ of the total surface of each optic nerve were photographed and counted (data from Cenni et al., in press).

tal death. Second, we examine whether the overexpression of bcl-2 can protect RGCs of newborn animals from axotomy, thus testing the efficacy of bcl-2 at promoting survival after transection of a nerve within the CNS.

\section{MATERIALS AND METHODS}

Animals. The production of transgenic mice has been described previously (Martinou et al., 1994). Two transgenic lines were used in this study: neuron-specific enolase promoter (NSE) 71 and NSE 73a/b. Males heterozygous for the transgene were crossed with $\mathrm{C} 57 \mathrm{Bl} / 6$ (wild-type) females. The presence of the bcl- 2 transgene was assessed by PCR on DNA from tail tissue of all the animals and in some cases confirmed by immunostaining of their retinas with anti-human Bcl-2 antibodies. Approximately one third of the pups were determined to be bcl-2-positive.

Surgery. On postnatal day 1-2 (P1-2; P0, day of birth), we performed unilateral intracranial optic nerve section. Surgery was performed on whole litters composed of both wild-type and bcl- 2 transgenic mates but before the genotype of the pups by PCR (blind procedure) was assessed. Mouse pups were anesthetized by hypothermia. The left optic nerve was transected intracranially by suctioning the overlying cortex through a syringe needle. The section was performed at a distance of $\sim 1 \mathrm{~mm}$ from the posterior pole of the eye. A total of 21 wild-type and $17 \mathrm{bcl}-2$ mice survived surgery and were used for subsequent study. Mice were allowed to recover and then nursed until they were killed $(18,24$, and $30 \mathrm{hr}$ postsurgery).

Histology. Animals were anesthetized with intraperitoneal injection of Avertine $(20 \mu \mathrm{l} / \mathrm{gm}$ body weight) and perfused transcardially with $4 \%$ paraformaldehyde, $0.1 \mathrm{M}$ cacodylate buffer, $\mathrm{pH} 7.2$, and $50 \mathrm{mM} \mathrm{CaCl}_{2}$. Each animal was perfused for $\sim 15 \mathrm{~min}$ by using a volume of fixative of 20 $\mathrm{ml}$. Eyes and proximal stumps of the optic nerves were dissected and processed separately.

Immunohistochemistry. For Bcl-2 immunostaining, eyes of both transgenic and wild-type newborn mice were rinsed in $0.1 \mathrm{M}$ phosphate buffer, infiltrated with $25 \%$ sucrose in the same buffer, and frozen at $-20^{\circ} \mathrm{C}$. Radial sections, $12 \mu \mathrm{m}$ thick, were cut at a cryostat and collected on gelatin-coated slides. Sections were rinsed in PBS solution and incubated in $10 \%$ bovine serum albumin (BSA), $0.3 \%$ Triton X-100, and PBS for 3 $\mathrm{hr}$, followed by incubation in fluoresceinated mouse monoclonal antihuman Bcl-2 antibody (Dako) diluted 1:100 with 1\% BSA, 0.1\% Triton $\mathrm{X}-100$, and PBS.

Analysis of surviving and pyknotic cells. Retinas were dissected, flattened on gelatinized slides, and fixed with $2.5 \%$ glutaraldehyde for $1 \mathrm{hr}$, followed by formaline-ethanol solution $(1: 9)$, for $4-7 \mathrm{~d}$. The whole-mount retinas were then stained with cresyl violet $(0.1 \%)$ and analyzed at the light microscope after a double-blind procedure. Pyknotic cells were counted in 15 retinas from wild-type mice and in 12 retinas from transgenic mice (all from the operated side). Living cells were counted on six retinas from wild-type mice and on seven retinas from bcl-2 transgenic mice. As controls, 4 bcl-2 retinas and 13 wild-type retinas, all from unoperated animals, were used for counting pyknotic cells; four retinas of each group were also used for counting living cells. An eyepiece graticule and a $100 \times$ oil immersion objective were used. The number of pyknotic profiles and the number of living cells were counted in the ganglion cell layer of $20(90 \times 90 \mu \mathrm{m})$ fields, equally distributed along the radius of the four quadrants of the whole-mount retinas, and covering $\sim 5 \%$ of their surface. The topographical arrangement of RGCs in the newborn mouse retina is uniform. We estimated the total number of cells per retina by multiplying the mean number of cells per field times the ratio of the total area of each retina to field area. Retinal areas were measured with a computer-assisted image analyzer. Pyknotic cells were identified in the ganglion cell layer by the presence of condensed and darkly stained nuclei, sometimes fragmented in separated bodies, as described by Perry et al., 1983. When two or more clumps were observed within a cell diameter, they were counted as one pyknotic cell.

In situ labeling of fragmented DNA (TUNEL). Whole eyes (six from wild-type and five from bcl-2 mice) were dissected from animals perfused as above, dehydrated in ethanol, embedded in paraffin, and sectioned at $6 \mu \mathrm{m}$ on a rotary microtome. Sections were collected on poly-lysinecoated slides, postfixed in $4 \%$ paraformaldehyde, and processed according to the technique described in Gavrieli et al. (1992) and Rabacchi et al. (1994a). Briefly, eye sections were treated with proteinase $\mathrm{K}(20 \mu \mathrm{g} / \mathrm{ml})$ to dissociate proteins from DNA and then incubated with terminal deoxynucleotidyl transferase $(0.3 \mathrm{U} / \mu \mathrm{l}$; Boehringer Mannheim) and biotinylated dUTP (40 $\mu \mathrm{M}$; Boehringer Mannheim). The reaction product was visualized with fluorescein-conjugated avidin D (Vector, Labtek). Labeled and unlabeled cells were counted with use of a Zeiss Axioplan microscope equipped with epifluorescence, using a $100 \times$ oil immersion objective. For each eye, three sections were selected that included the optic nerve head. All of the cells contained in the ganglion cell layer were counted in 40-60 fields (90 $\mu \mathrm{m}$ long) to cover the full length of each section. An average number of 1500 cells was counted for each retinal section. TUNEL-positive cells were counted separately, and their number was expressed as a function of the total number of cells in the ganglion cell layer. The same three retinal sections used for each eye for counting TUNEL-positive profiles were counterstained with cresyl violet. Pyknotic and normal cells were counted in the ganglion cell layer, again covering the full extension of each section. The number of pyknotic cells was expressed as a function of the total number of cells in the ganglion cell layer. All values shown in Results are expressed as mean \pm SD.

Analysis of the optic nerve. The proximal stumps of the transected optic nerves were postfixed at $4^{\circ} \mathrm{C}$ in $1.25 \%$ glutaraldehyde, $2 \%$ paraformaldehyde, $0.1 \mathrm{M}$ cacodylate buffer, $\mathrm{pH} 7.2$, and $50 \mathrm{mM} \mathrm{CaCl}_{2}$, for $12-18 \mathrm{hr}$. After they were rinsed in cacodylate buffer, the nerves were immersed in $1 \%$ osmium tetroxide, stained en bloc with $1 \%$ uranyl acetate in maleate buffer, dehydrated in a graded series of ethanol, and embedded in Epon-Araldite. Semithin (1-2 $\mu \mathrm{m}$ thick) sections were collected from each specimen and stained with toluidine blue for light microscopy. Ultrathin sections were stained with uranyl acetate and lead citrate and examined with a Jeol 1200 EXII electron microscope. Twelve transected nerves and three intact nerves from wild-type animals and four transected nerves from bcl-2 animals were processed for light and electron microscopy.

PCR analysis. Before perfusion, a piece of tail was cut from each animal and frozen at $-80^{\circ} \mathrm{C}$. The tail segments were cut into small pieces and then homogenized in tail buffer $(0.3 \mathrm{M}$ sodium acetate, $100 \mathrm{mM}$ Tris- $\mathrm{HCl}$, $\mathrm{pH}$ 8.0, $1 \mathrm{~mm}$ EDTA, $\mathrm{pH} 8.0,1 \% \mathrm{SDS}$, and $10 \mathrm{mg} / \mathrm{ml}$ proteinase $\mathrm{K}$ ). Protein components were removed by phenol/chloroform/isoamylic alcohol (10:10:1) extraction, and the genomic DNA was recovered by isopropylic alcohol. The reaction made use of two oligonucleotide primers that hybridize to opposite strands and flank the target DNA sequence. The elongation of the primers was catalyzed by Taq DNA polymerase (Promega). Human bcl-2 gene was detected by a series of 40 amplification cycles using a Perkin/Elmer apparatus.

\section{RESULTS}

We have used two lines (NSE 73a/b and NSE 71) of transgenic mice in which neurons overexpress the human bcl-2 gene under the control of the NSE (Martinou et al., 1994). The effects of bcl-2 overexpression, both during the period of natural cell death and after optic nerve transection, have been evaluated by examining different markers of degeneration (pyknosis and DNA fragmentation) as well as neuronal survival.

Immunohistochemical studies revealed that only line NSE $73 \mathrm{a} / \mathrm{b}$ is expressing high levels of human $\mathrm{Bcl}-2$ protein in the retina (Fig. 1B), whereas the second line (NSE 71) (data not shown) and the wild-type animal (Fig. $1 A$ ) did not exhibit any signal. Therefore the second line NSE 71 was used in some cases as a negative control. As illustrated in Figure $1 C$, ganglion cells of the newborn transgenic retina show intense immunoreactivity, whereas most of the other cell types, still undifferentiated at this developmental stage, are negative. Only a weak signal begins to be exhibited by the adjacent differentiating amacrine cells. 

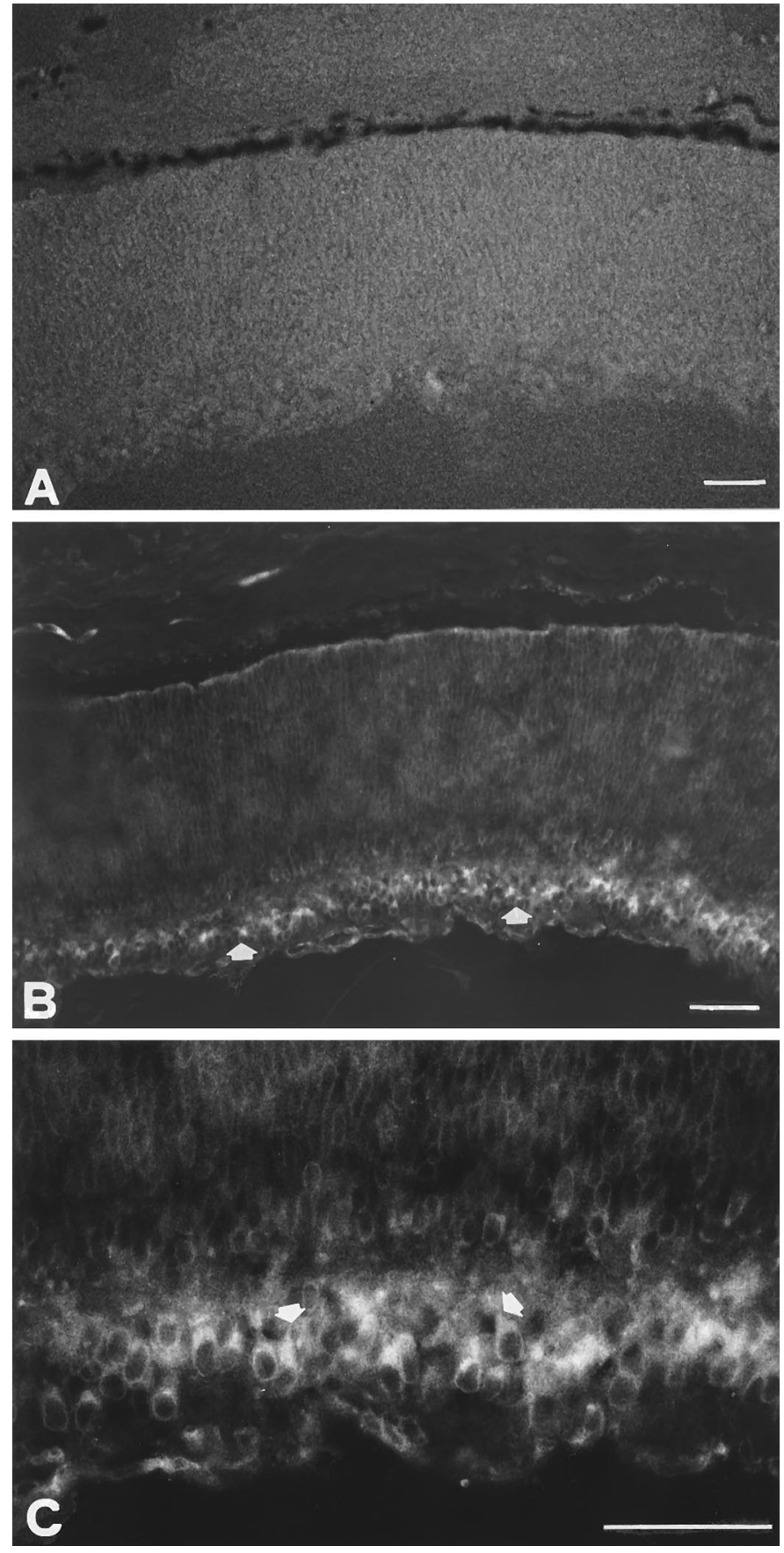

Figure 1. Immunostaining for the human Bcl-2 protein in radial sections of neonatal retina. $A$, Wild-type mouse retina showing no staining. Print has been underexposed to allow visualization of the structure. $B$, bcl-2 transgenic mouse retina, line NSE $73 \mathrm{a} / \mathrm{b}$, showing high levels of human $\mathrm{Bcl}-2$ protein in the ganglion cells (white arrows). $C$, High magnification of $B$. Apical dendrites of ganglion cells are visible (white arrows); nuclei are negative. Some differentiating cells in the inner nuclear layer (most probably amacrine cells) show weak immunoreactivity. Eventually all retinal neuronal classes except for photoreceptors will express the human Bcl-2 protein in this line of transgenics. Scale bars, $50 \mu \mathrm{m}$.

\section{Rescue of RGCs from naturally occurring cell death}

Like many other neurons, RGCs also undergo a period of naturally occurring cell death. In rats, $\sim 50 \%$ of RGCs die during the first 10-14 postnatal days (Perry et al., 1983; Horsburgh and Sefton, 1987). Similarly, in the retina of the mouse, up to $60 \%$ of ganglion cells die between P0 and adulthood (Williams et al., 1990). It has been demonstrated that at birth the ganglion cell layer of the rat retina is constituted almost entirely of ganglion cells (Perry et al., 1983; Rabacchi et al., 1994a). As the retina matures, an increasing proportion of the neurons in this layer is represented by amacrine cells, which reach $50 \%$ of all the cells in the adult (Perry, 1981).

To establish what fraction of cells in the ganglion cell layer of the neonatal mouse retina is represented by ganglion cells alone, we counted the total number of cells of the layer in P1 retinal whole mounts that were stained with cresyl violet, and we compared this total with the number of ganglion cell axons determined by Williams and colleagues (1990) at P0. We find that the total number of cells in the RGC layer at P1 $(115,000$; Table 1) is approximately equal to the number of fibers in the optic nerve at P0 $(128,000)$ (Williams et al., 1990). We conclude, therefore, that similar to those of the rat, virtually all cells found in this layer of newborn mouse retina are indeed ganglion cells.

To determine whether and to what extent bcl- 2 overexpression is capable of rescuing ganglion cells that would normally die during development, we analyzed degenerating and surviving ganglion cells during the period of naturally occurring cell death in transgenic (NSE 73a/b) and wild-type mouse pups. We analyzed retinas of 1- to 2-d-old mice, which corresponds to an early stage in the period of natural cell death for ganglion cells (Hume et al., 1983). The number of pyknotic ganglion cells counted in wholemount retinas stained with cresyl violet was significantly lower in bcl-2 transgenic animals $(384 \pm 91$ pyknotic cells/retina) than in wild-type mice $(3300 \pm 970$ cells/retina; $p<0.001)$ (Fig. 2).

In the same retinas, we also determined the total number of living cells in the ganglion cell layer (Table 1). By comparing the number of ganglion cells in P1-2 retinas with the number of ganglion cell axons present in the adult, it is evident that almost $60 \%$ of RGCs die between birth and adulthood in the wild-type mouse. The number of RGCs found in the adult bcl-2 retina, however, is not statistically different from their number in the retina at P1 (Table 1). This shows that overexpression of bcl-2 is capable of rescuing the vast majority of RGCs normally undergoing natural cell death between P1-2 and adulthood. This is not the case in other areas of the nervous system, where natural cell death can be prevented only partially by the overexpression of bcl-2 (Martinou et al., 1994; Farlie et al., 1995). It should be noted, however, that a small fraction of pyknotic cells is actually found in the RGC layer of P1-2 transgenic animals $(0.3 \%)$ and that we did not take into account those ganglion cells that might have died earlier than P1.

\section{Protection from axotomy-induced cell death}

To test whether the overexpression of human Bcl-2 protein could protect axotomized ganglion cells from death, we performed a transection of the optic nerve on P1-2 pups on both lines of bcl-2 transgenic mice $(73 \mathrm{a} / \mathrm{b}$ and 71$)$ as well as on their littermates of wild-type genotype. We showed previously that a section to the optic nerve in the neonatal rat induces the appearance of chromatin condensation (pyknosis) in ganglion cells (Miller and Oberdorfer, 1981; Beazley et al., 1987; Rabacchi et al., 1994a) as well as nuclear DNA fragmentation, as assessed by applying a method of in situ detection of DNA fragmentation (TUNEL) (Gavrieli et al., 1992; Rabacchi et al., 1994a). We therefore examined the appearance of pyknotic cells and DNA fragmentation in wild-type and bcl-2 transgenic animals after transection of the optic nerve.

We determined the time course of degeneration of axotomized 

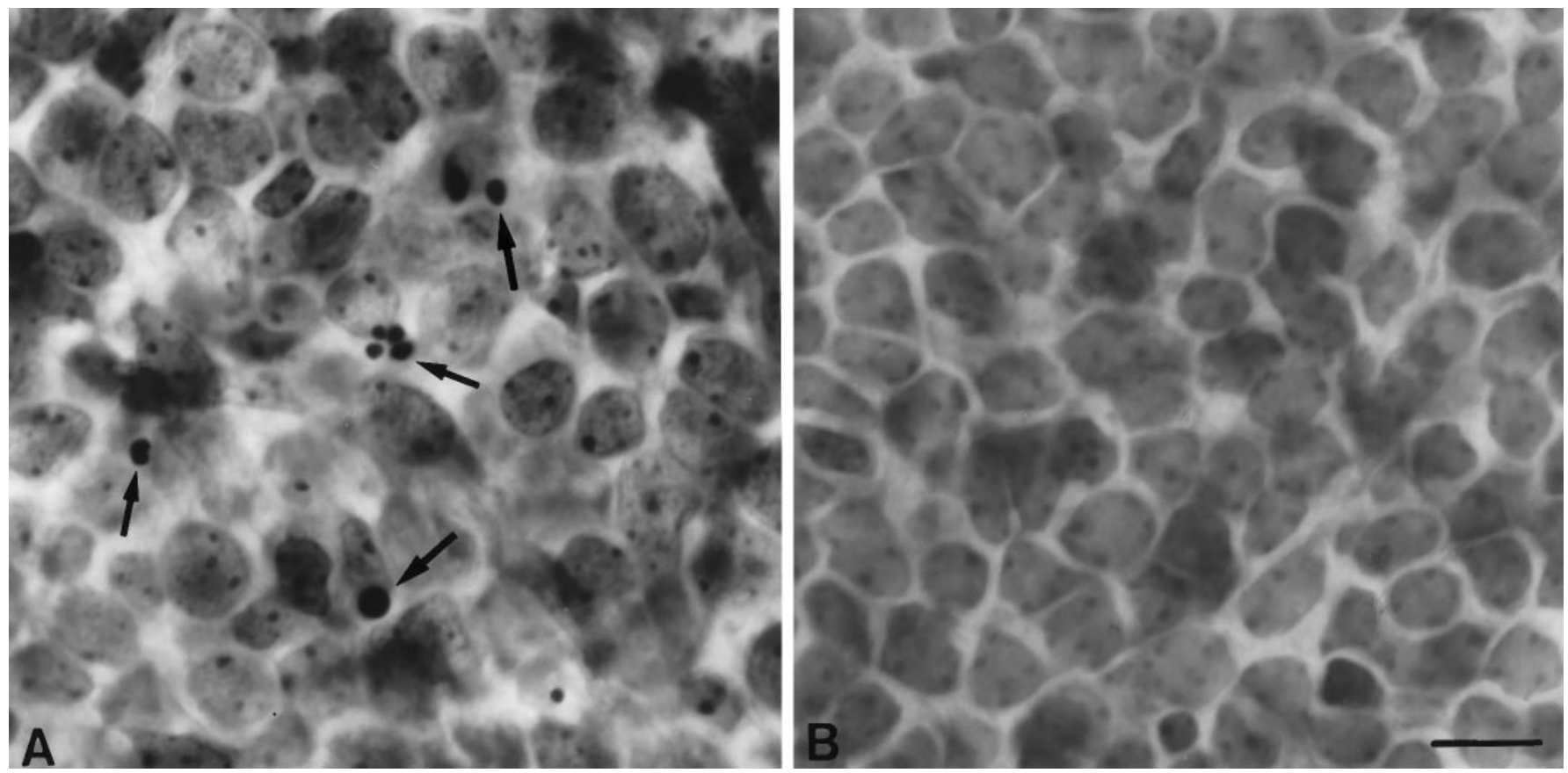

Figure 2. Natural cell death of retinal ganglion cells from wild-type and bcl-2 transgenic mice. Light micrographs of the ganglion cell layer of whole-mount retinas stained with cresyl violet at P1-2. A, Wild-type mouse; arrows point to pyknotic nuclei. $B$, bcl-2 transgenic mouse, at corresponding location and focal plane shown in $A$. No pyknotic profiles are visible in this field. Scale bar, $10 \mu \mathrm{m}$.

RGCs in the wild-type neonatal mouse by counting pyknotic cells in the RGC layer. On the basis of previous data on the rat (Rabacchi et al., 1994a), we selected three time points: 18, 24, and $30 \mathrm{hr}$ after transection. As shown in Figure $3 A$, the peak period of degeneration occurred at $\sim 24 \mathrm{hr}$ postsurgery. We therefore focused on the 24 and $30 \mathrm{hr}$ time points.

\section{Analysis of pyknotic and surviving RGCs after axotomy}

As illustrated in Figure 4, transection of the optic nerve in wildtype mice induces the massive appearance of pyknotic profiles, characterized by one or more clumps of condensed chromatin that are confined to the RGC layer. In contrast, pyknotic cells are encountered only rarely in the ganglion cell layer of bcl-2 transgenic animals at the same time after the lesion.

Indeed, although an average number of 71,000 pyknotic cells were found in the wild-type retinas at $24 \mathrm{hr}$, only 4300 pyknotic cells were counted in the bcl-2 retinas $(p<0.001)$ (Fig. $3 A$ ). Even at $30 \mathrm{hr}$ postsurgery, the number of pyknotic cells in the ganglion cell layer was still much lower in the transgenic animals compared with that of their wild-type littermates (2200 vs 29,$900 ; p<$ $0.0001)$. The analysis of retinas deriving from the transgenic line NSE 71 revealed the absence of protection from degeneration in axotomized ganglion cells, as judged by the massive pyknosis found in the ganglion cell layer of this strain of transgenics. This result is consistent with the lack of expression of human Bcl-2 protein in RGCs in this particular line of transgenic mice (data not shown) (Martinou et al., 1994).

To confirm that the overexpression of bcl-2 results in a true increase in the survival of ganglion cells and that the reduction of pyknosis observed is not simply attributable to other factors, including a faster clearance rate of degenerating cells, we counted the number of cells surviving in the ganglion cell layer of the same retinas that were used for counting pyknotic profiles at $24 \mathrm{hr}$ and $30 \mathrm{hr}$ postsurgery. Although $50 \%$ of the ganglion cells seemed to have degenerated in wild-type animals at $24 \mathrm{hr}$ postlesion, no cell loss could be detected in the bcl-2 transgenic mouse at the same time. Even at $30 \mathrm{hr}$ postlesion, the number of surviving neurons in bcl-2 transgenic animals did not differ significantly from that of the control retinas (Fig. $3 B$ ).

\section{Analysis of cells with DNA fragmentation}

We analyzed another typical feature emerging as a result of axotomy in the neonatal rodent retina, namely the fragmentation of nuclear DNA detected in situ by means of the TUNEL technique (Gavrieli et al., 1992). This technique was used on retinal sections from wild-type and bcl-2 transgenic mouse pups before and after transection of the optic nerve. As illustrated in Figure 5, a large number of nuclei are labeled in the ganglion cell layer of wild-type retinas at $24 \mathrm{hr}$ postlesion (Fig. 5A); overexpression of Bcl-2 protein largely prevents the fragmentation of DNA in these cells (Figs. $5 B$ and 6). A few scattered cells were also found to be labeled in the ventricular cell stratum in both the unlesioned (data not shown) and lesioned wild-type retinas. This is consistent with the presence of nonidentified, undifferentiated pyknotic cells observed previously in the same area by others (Young, 1984) and by us (Rabacchi et al., 1994a).

When the same sections in which TUNEL-positive cells had been counted were counterstained with cresyl violet for quantification of pyknotic cells, we observed that the number of cells stained with the two methods was comparable (data not shown), thus confirming that in our system the two techniques can be used interchangeably (also see Rabacchi et al., 1994a).

\section{Analysis of the structure of the optic nerve}

In a parallel work investigating the effects of axotomy on RGCs in adult mice overexpressing the human bcl-2 gene, we observed a protective effect on both the cell bodies and the axons of the severed neurons (Cenni et al., 1995; Cenni et al., in press). To 

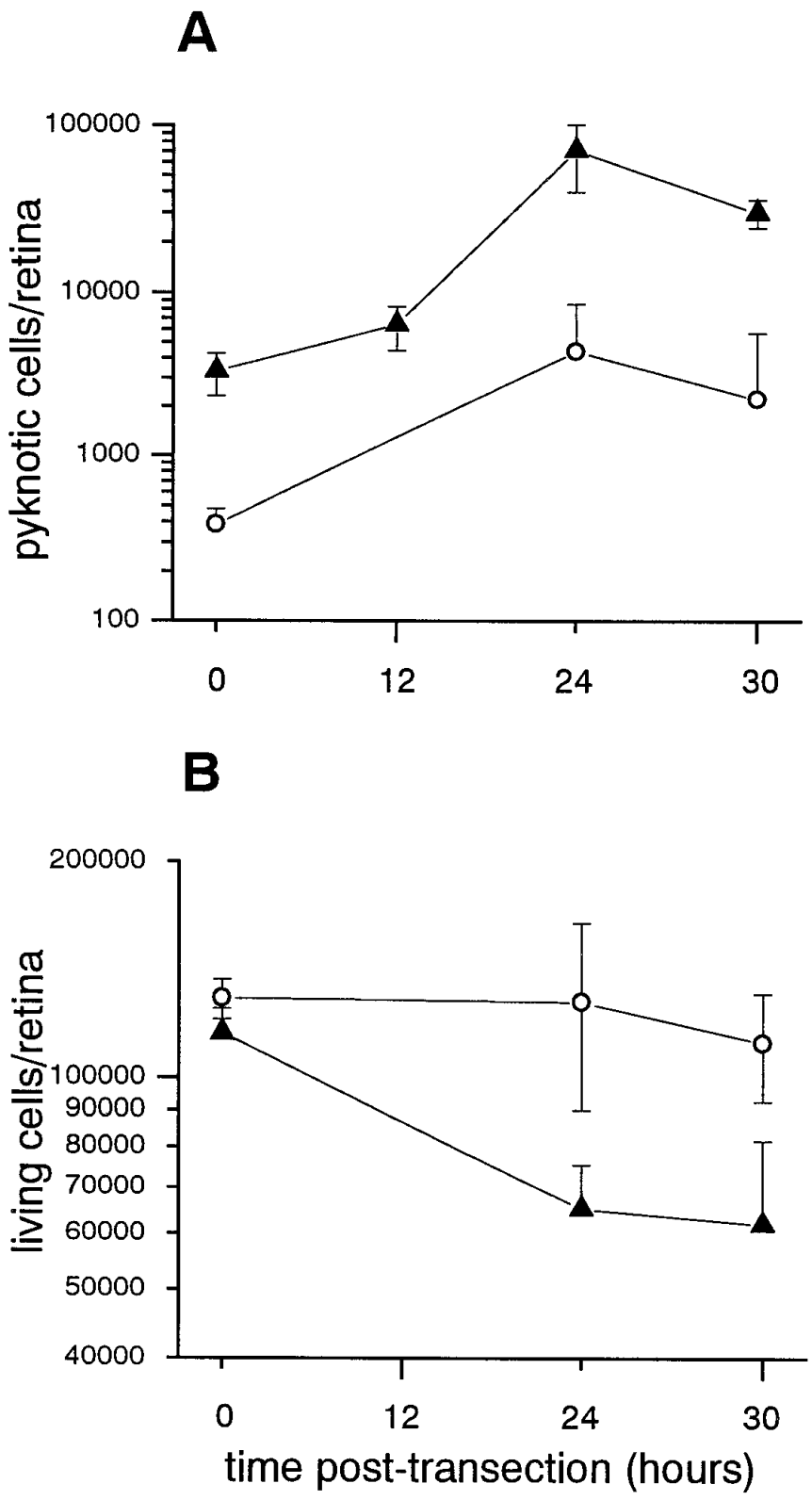

Figure 3. Pyknosis in the RGC layer. A, Time course of the appearance of pyknotic cells in the ganglion cell layer of wild-type (black triangles) and bcl-2 transgenic mice (open circles) after transection of the optic nerve. $B$, Time course of the reduction in the number of living cells in the ganglion cell layer of wild-type (black triangles) and bcl-2 transgenic mice (open circles) after the transection of the optic nerve.

verify whether such protecting action was also present in axotomized ganglion cell fibers of newborn animals, we examined the structure of the proximal stumps of transected nerves from newborn bcl-2 and wild-type mice (Fig. 7).

Compared with wild-type unlesioned nerves from animals of the same age, the histological section of a wild-type nerve $24 \mathrm{hr}$ after transection shows signs of profound alteration. Astrocytic processes, usually forming a regular plexus across the nerve surface, are no longer visible with the light microscope, having lost continuity from the parent cell bodies. The surface of the nerve normally occupied by fibers appears desegregated in empty spaces. In bcl-2-transected nerves examined at similar distances from the eye, modifications appear less dramatic in three of the four animals examined: astrocytes are disorganized only in restricted areas of the nerve, and the general morphology seems normal. Electron microscopy, however, shows similar alterations in the axons of both wild-type and bcl-2 transgenic nerves: fibers acquire various sizes and exhibit irregular shapes. Many of them appear swollen, and anomalous tubular and vesicular profiles completely fill their lumen. It seems likely that the increase in number and size of such membranous structures eventually results in the rupture of the fiber membrane, with the subsequent formation of debris and empty spaces.

\section{DISCUSSION \\ Natural cell death}

The present results demonstrate that the overexpression of the bcl-2 gene is effective in preventing the degeneration of ganglion cells attributable to naturally occurring cell death. We show that the vast majority $(90 \%)$ of RGCs that normally die during early development is rescued by bcl-2 overexpression. Previous observations of a higher cell density within the RGC layer and enlargement of optic nerves in bcl-2 transgenics (Martinou et al., 1994) suggested a relationship between overexpression of the protein and the appearance of supernumerary ganglion cells in the adult. In that study, however, the ganglion cell population was not distinguished from neighboring amacrine cells, nor were surviving neurons quantified. Here we take advantage of the homogeneity of the ganglion cell layer in neonatal animals and find that the number of degenerating ganglion cells during the period of natural cell death is substantially reduced in bcl-2 transgenics. This result supports the hypothesis that the presence of supernumerary ganglion cells in the adult transgenic animal is attributable to a reduction of cell death during development rather than to changes in other developmental processes, such as proliferation or differentiation. Furthermore, to quantify cell survival in the adult, we compare the number of ganglion cells present in the early retina with the number of ganglion cell axons present in the adult.

The process of natural cell death in the wild-type mouse retina has not been investigated in detail. It is impossible to indicate the precise number of ganglion cells undergoing natural cell death, because data on the initial number of ganglion cells present in the embryonic mouse retina are not available. Hume and colleagues (1983), however, have shown that pyknosis in the prenatal retina is low and that the peak in ganglion cell death is in the early postnatal age. We find that $\sim 60 \%$ of ganglion cells are lost between P1 and adulthood in wild-type retinas and that a similar fraction is prevented from undergoing natural cell death in bcl-2 retinas. Hence, our conclusion is that most of the ganglion cells that would die naturally during the early postnatal development are rescued in bcl-2 transgenic mice.

It is worth noting that overexpression of bcl- 2 is considerably more effective in rescuing RGCs from developmental cell death than it is in neurons from other areas of the nervous system (i.e., facial motoneurons, neurons of the mesencephalic nucleus of the trigeminal nerve, and L5 dorsal root ganglion sensory neurons) (Martinou et al., 1994; Farlie et al., 1995). It has been inferred that multiple cell death pathways exist, presumably reflecting the dependence for survival on different trophic factors. It is possible that RGCs represent a population with more homogenous requirements for survival, i.e., dependence on relatively similar trophic factors, and that the overexpression of bcl-2 is able to counteract the lack of these factors. For RGCs, therefore, the existence of bcl-2-independent survival mechanisms does not seem to play a major role during development. Our data, however, 

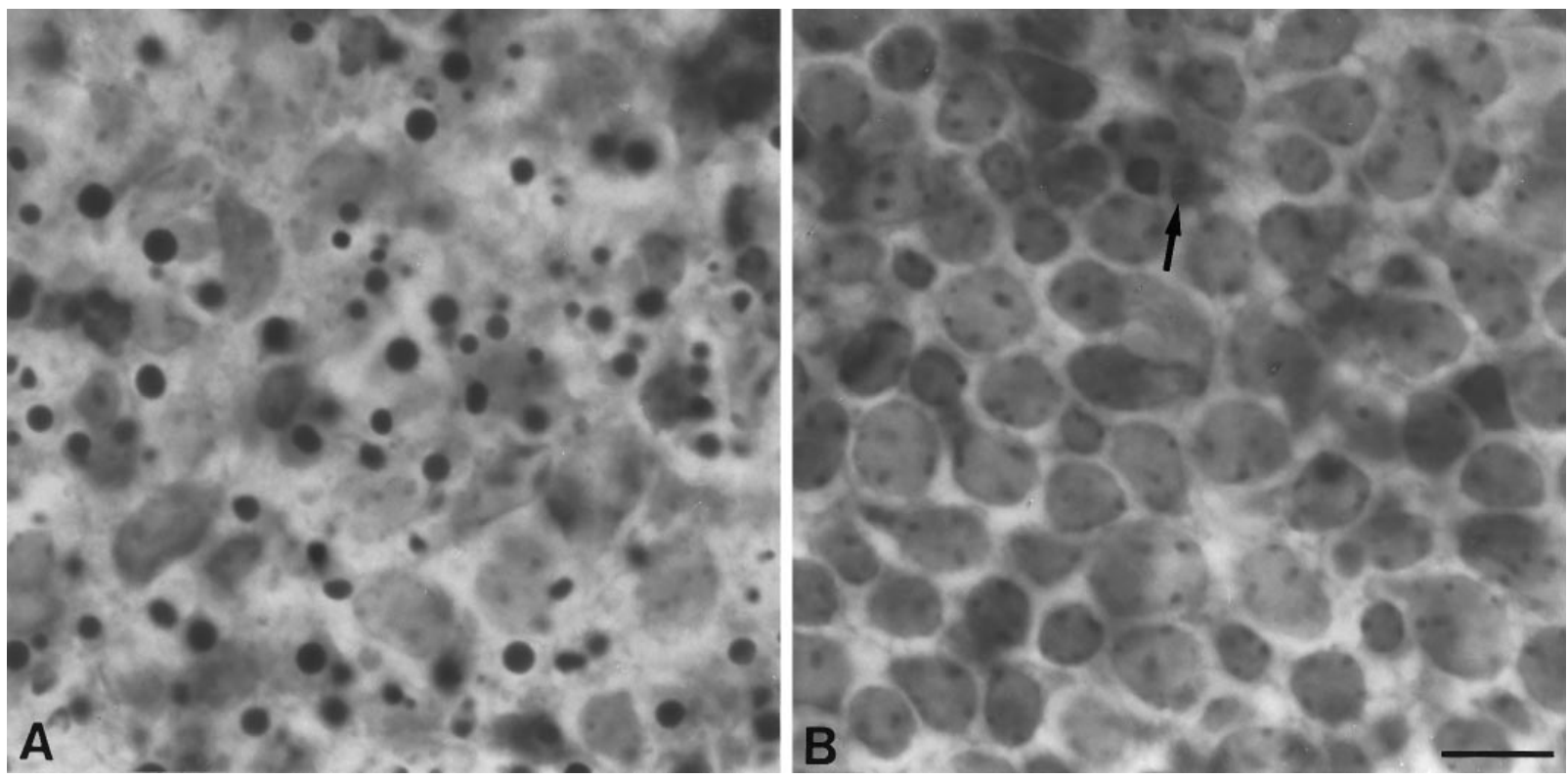

Figure 4. Effects of optic nerve transection on RGCs in wild-type and bcl-2 animals at $24 \mathrm{hr}$ postlesion. Light micrographs of the ganglion cell layer of whole-mount retinas stained with cresyl violet at $\mathrm{P} 1-\mathrm{P} 2$. $A$, Wild-type mouse, exhibiting numerous apoptotic cells; $B$, bcl-2 transgenic mouse, where only one apoptotic cell is visible (arrow). Scale bar, $10 \mu \mathrm{m}$.

do not rule out the participation of other molecules sharing similar signal pathways, some of which have been identified recently (Davies, 1995).

Both the mechanisms regulating bcl-2 expression and the transduction pathways used by bcl-2 itself have not yet been elucidated completely (Hockenbery et al., 1993). The notion that extracellular signals such as trophic factors can regulate neuronal survival suggests that they may accomplish their effects by regulating bcl-2 activity. Data supporting this hypothesis derive from experiments in which the inhibition of bcl-2 expression by antisense oligonucleotides prevents the survival-promoting activity of brain-derived neurotrophic factor (BDNF) (Allsopp et al., 1995). Consistent with these data, the survival of RGCs increases, either in vitro or after section of the optic nerve, when BDNF (normally present in the tectal target tissue) or other members of the neurotrophin family (Johnson et al., 1986; Carmignoto et al., 1989; Mey and Thanos, 1993; Berkelaar et al., 1994; Rabacchi et al., 1994b) are administered. To provide additional evidence for the hypothesis that the endogenous expression of bcl-2 plays a role in the regulation of survival of RGCs during normal development, it will be important in the future to study its distribution in the developing retina, as has been done for other areas of the CNS (Merry et al., 1994). From the present experiments, we cannot rule out the possibility that the overexpression of bcl-2 may have an additional indirect effect on ganglion cell survival by increasing the size of target structures such as the tectum, which actually appears enlarged in transgenic mice; however, neither the expression of human Bcl-2 protein nor the number of retino-recipient cells in the tectum have been evaluated in the transgenics. On the other hand, presynaptic influences are unlikely, because afferent inputs to RGCs develop several days after birth in the rodent retina (Horsburgh and Sefton, 1987).

\section{Protection from axotomy-induced cell death}

For this study, we used three main criteria for establishing the effects of optic nerve transection on RGCs in newborn mice. (1) We estimated the number of pyknotic cells appearing in the RGC layer, as an effect of surgery; (2) we quantified the presence of surviving neurons in this same layer; and (3) because recent findings suggest that pyknosis alone might be a poor indicator of cell death (Wood et al., 1993), we analyzed another feature of degeneration, namely the fragmentation of nuclear DNA in ganglion cells, using the TUNEL technique (Gavrieli et al., 1992). Interestingly, the number of cells displaying DNA fragmentation closely resembles the number of pyknotic cells, when counted on the same retinal section, in both the wild-type and bcl-2 preparations. Consistently, $24 \mathrm{hr}$ after the transection of the optic nerve, both pyknosis and DNA fragmentation are reduced by $90 \%$ in bcl-2 transgenic mice.

Overexpression of the human bcl-2 gene is therefore able to protect ganglion cells of the neonatal retina from degeneration induced by optic nerve transection. Although a high proportion $(50 \%)$ of ganglion cells have already degenerated in wild-type animals 24 after axotomy, only very few disappeared in the bcl-2 transgenic mouse at that time. This number does not increase substantially $30 \mathrm{hr}$ postsurgery, even though this time point represents a rather late phase in the degeneration process induced by axotomy (Fig. $3 A$ ). As a consequence, the number of cells that survive after 24 and $30 \mathrm{hr}$ in bcl-2 retinas is indeed close to the number of ganglion cells found in intact transgenic retinas of the same age.

The question of whether overexpression of bcl-2 is capable of preventing the degeneration of the axotomized neurons indefinitely, or rather of delaying their degeneration, remains unsolved, mainly because of difficulties in protracting the survival time of mouse pups beyond $30 \mathrm{hr}$ postsurgery; however, the lack of an increase in pyknosis at $30 \mathrm{hr}$ observed in transgenic animals and the preservation of the number of surviving cells at this late stage suggest that the protective effect of bcl-2 may be long-lasting. In a parallel study on the effects of optic nerve transection on adult bcl-2 transgenic mice, we showed that axotomized ganglion cells survive in large number even at 3.5 months after surgery, retaining an almost intact proximal segment of their axon and showing 


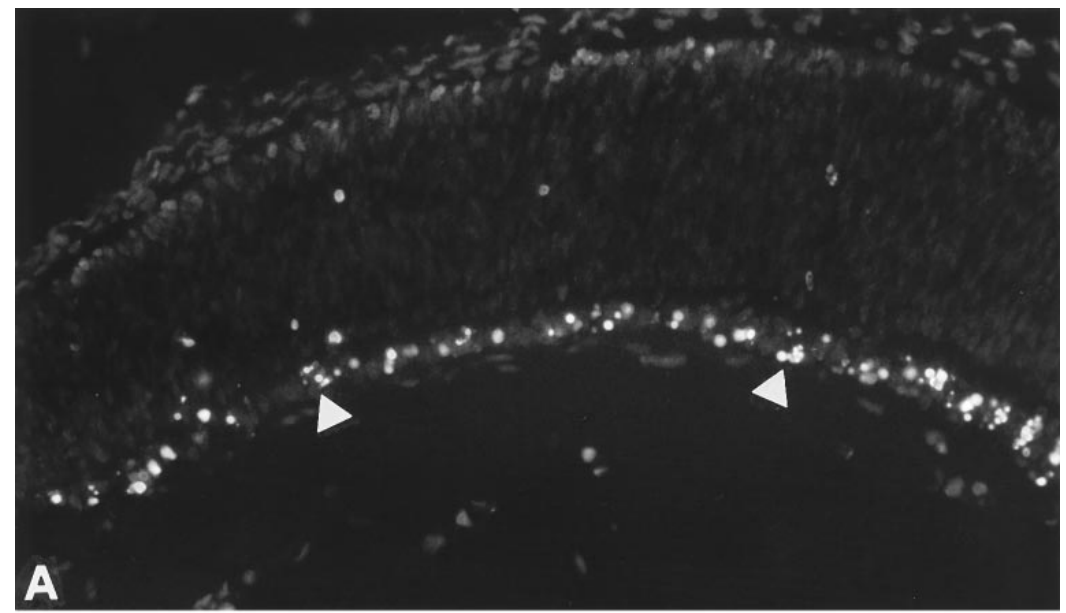

Figure 5. In situ labeling of DNA fragmentation (TUNEL) in retinal sections $24 \mathrm{hr}$ after optic nerve transection. Radial section of wild-type $(A)$ and bcl-2 transgenic $(B)$ retinas, where TUNEL-positive nuclei appear as white fluorescent profiles against a black background, particularly in the wildtype RGC layer (arrowheads). Scale bar, $50 \mu \mathrm{m}$.

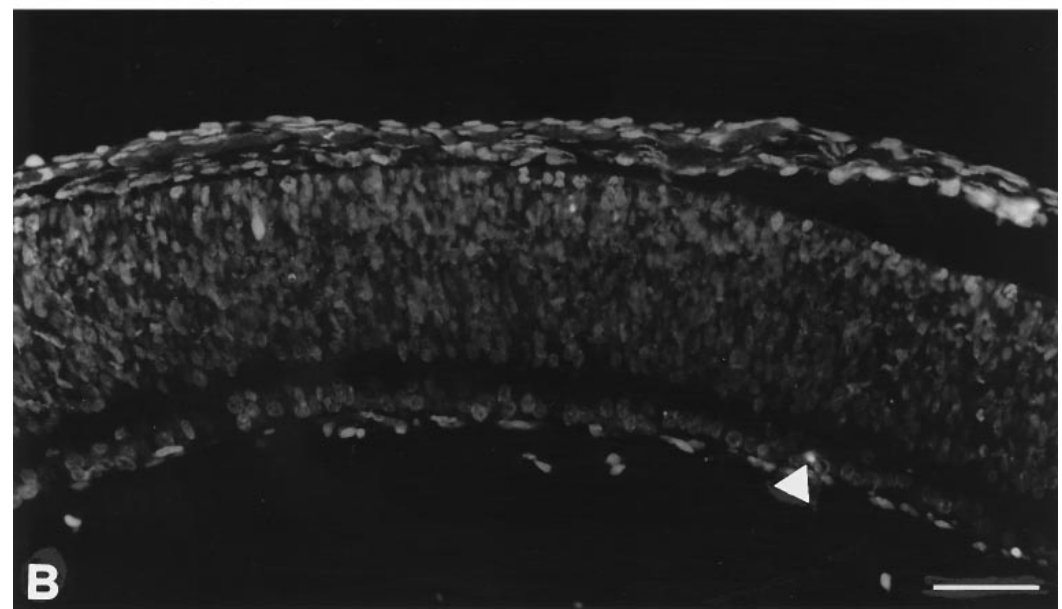

normal electrophysiological responses to light (Cenni et al., 1995; Porciatti et al., 1995). These data substantiate an enduring effect of the bcl-2 gene on neuronal survival.

The protective action of bcl-2 overexpression on transected axons observed in the adult ganglion cells cannot be extended to the axons of ganglion cells axotomized in the newborn animal, because in the present study we report ultrastructural alterations of both wild-type and transgenic fibers, although less dramatic in the latter case. Because we could not follow the morphological changes taking place in the optic nerve stumps of bcl-2 mice for long time intervals, we do not know whether these changes are reversible. This seems unlikely, however, because the observed alterations are basically similar to those noticed in wild-type nerves, which inevitably degenerate soon after. This result is not surprising considering the intrinsic differences between ganglion cells of the adult and immature retinas. Developing cells, still lacking intraretinal synaptic inputs and surrounded by immature glial cells in the optic nerve, could be more critically dependent on trophic molecules released by their targets for the maintenance of their normal morphology. A similar condition can be found in cultured neuronal cells that are strictly dependent on the exogenous supply of trophic molecules. Actually, in these cells the forced expression of bcl-2 does stop neuronal death after withdrawal of the trophic factors, but it is unable to prevent neuritic retraction and cell body shrinkage (Garcia et al., 1992; Farlie et al., 1995). It is possible that partially distinct mechanisms exist for the regulation of neuronal survival, on the one hand (in which bcl-2 acts powerfully), and for the maintenance of a differentiated phenotype, on the other (in which trophic factors might play a more crucial role).

In conclusion, the remarkable rescue capacity of bcl-2 overexpression in RGCs makes it an interesting experimental model for the study of both natural cell death and cellular responses triggered by traumatic injuries to central neurons.

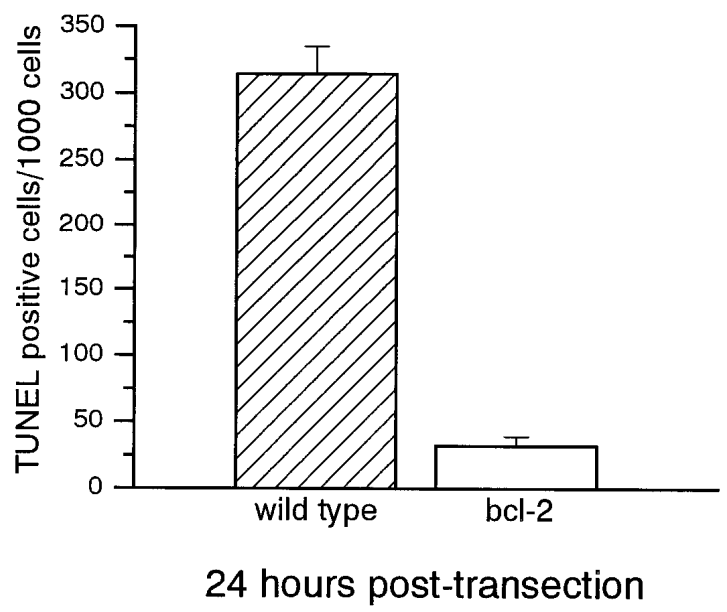

Figure 6. Effects of optic nerve transection on DNA fragmentation of RGCs. TUNEL-positive cells counted in retinal sections of wild-type and bcl-2 transgenic mice $24 \mathrm{hr}$ after section of the optic nerve. Bars represent the number of labeled cells for every 1000 cells of the ganglion cell layer. 

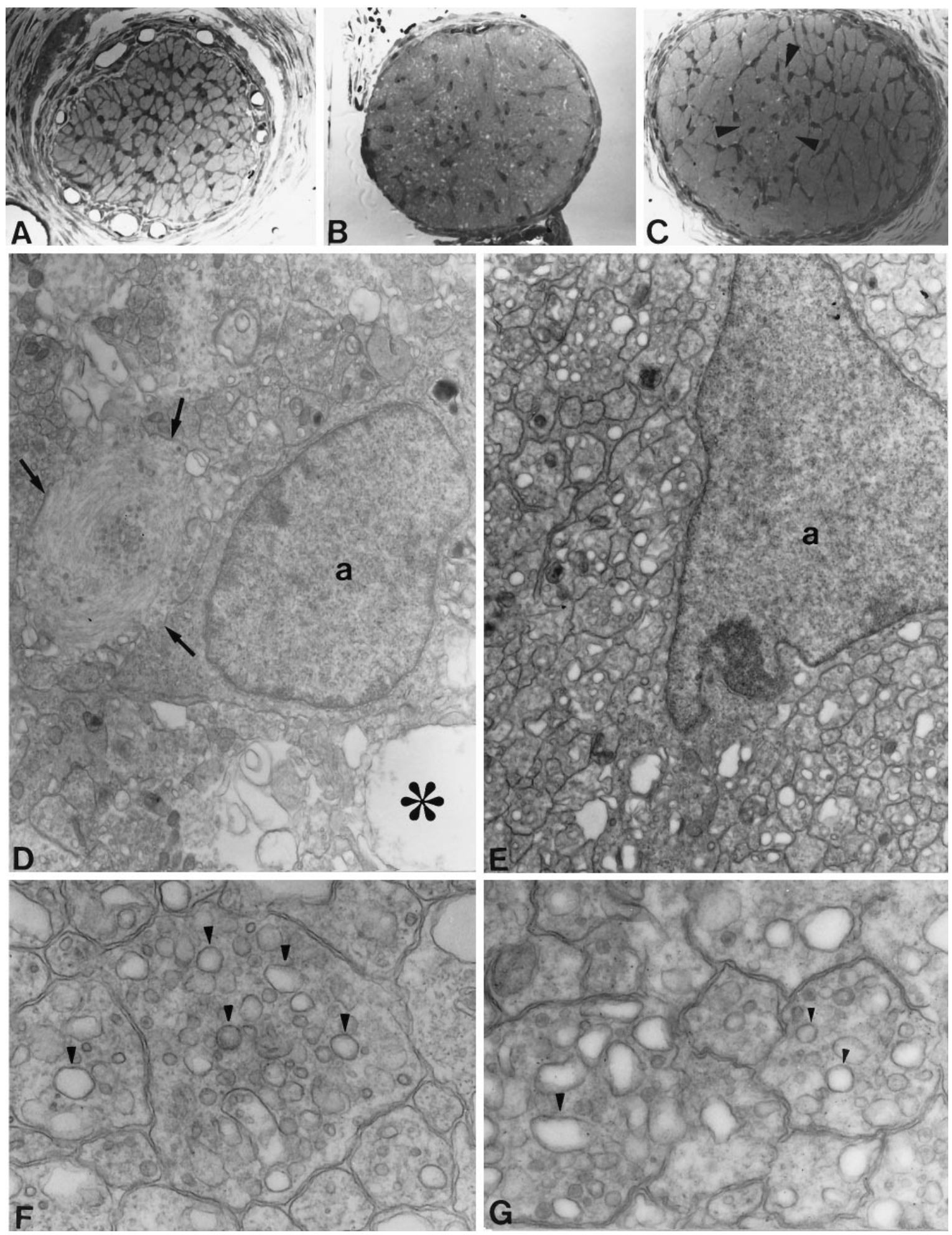

Figure 7. Morphology of wild-type and bcl-2 optic nerves $24 \mathrm{hr}$ after transection. $A$, Section $(1 \mu \mathrm{m}$ thick) of intact, wild-type optic nerve, in the proximity of the posterior pole of the eye. Astrocytic processes form a regular plexus across the whole surface of the nerve. $B$, Proximal stump of the optic nerve of a wild-type mouse $24 \mathrm{hr}$ after transection. Same location as in $A$. Note that astrocytic bodies appear isolated because their processes are no longer visible. The matrix shows white spaces. $C$, Proximal stump of bcl-2 optic nerve $24 \mathrm{hr}$ after transection. Astrocytic desegregation is restricted to a limited area (arrowheads). The remaining part of the nerve appears normal. Scale bar: $A-C, 200 \mu \mathrm{m}$. $D$, E. Electron micrographs of specimens shown in $B$ and $C$, respectively. The morphology of the nerve of the wild-type mouse $(D)$ is altered profoundly. Arrows point to a bundle of astrocytic filaments indicating a glial reaction. The asterisk indicates the empty space left from degenerating fibers. These changes are much less prominent in the nerve of the bcl-2 transgenic mouse $(E) . a$, Astrocytic nucleus. Scale bar: $F, G, 1 \mu \mathrm{m}$. High-magnification micrographs of preparations shown in $D$ and $E$, respectively. Single axons of both wild-type $(F)$ and bcl-2 $(G)$ optic nerves have undergone similar modifications. Fibers are swollen, and anomalous tubular and vesicular profiles fill their lumen (arrowheads). The normal ultrastructure of the fibers, with their complement of microtubules and intermediate filaments, is totally lost. Scale bar, $0.2 \mu \mathrm{m}$. 
Our results also show that the overexpression of bcl-2 in vivo is a powerful tool for circumventing the problem of rapid neuronal degeneration after a lesion to the CNS, making it possible to determine more effectively the issue of regeneration of nerve cells.

\section{REFERENCES}

Allsopp TE, Kiselov S, Wyatt S, Davies AM (1995) Role of bcl-2 in the brain-derived neurotrophic factor survival response. Eur J Neurosci 7:1266-1272.

Allsopp TE, Wyatt S, Patterson HF, Davies AM (1993) The protooncogene bcl-2 can selectively rescue neurotrophic factor-dependent neurons from apoptosis. Cell 73:295-307.

Beazley LD, Perry VH, Baker B, Darby EJ (1987) An investigation into the role of ganglion cells in the regulation of division and death of other retinal cells. Dev Brain Res 33:169-184.

Berkelaar M, Clarke DB, Wang Y-C, Bray GM, Aguayo AJ (1994) Axotomy results in delayed death and apoptosis of retinal ganglion cells in adult rats. J Neurosci 14:4368-4374.

Carmignoto G, Maffei L, Candeo P, Canella R, Comelli C (1989) Effect of NGF on the survival of rat retinal ganglion cells following optic nerve section. J Neurosci 9:1263-1272.

Catsicas S, Thanos S, Clarke PGH (1987) Major role for neuronal death during brain development: refinement of topographical connections. Proc Natl Acad Sci USA 84:8165-8168.

Cenni MC, Strettoi E, Bonfanti L, Ratto GM, Rabacchi SA, Martinou JC, Maffei L 1995 Long term survival of retinal ganglion cells following optic nerve transection in bcl-2 transgenic mice: anatomy. Soc Neurosci Abstr 21:1556.

Cenni MC, Bonfanti L, Martinou J-C, Ratto GM, Strettoi E, Maffei L (1995) Long term survival of retinal ganglion cells following optic nerve section in adult $b c l-2$ transgenic mice. Eur J Neurosci, in press.

Cowan WM, Fawcett JW, O'Leary DDM, Stanfield BB (1984) Regressive events in neurogenesis. Science 225:1258-1265.

Davies AM (1995) The Bcl-2 family of proteins and the regulation of neuronal survival. Trends Neurosci 18:355-358.

Dubois-Dauphin M, Frankowski H, Tsujimoto Y, Huarte J, Martinou J-C (1994) Neonatal motoneurones over-expressing the bcl-2 protooncogene in transgenic mice are protected from axotomy-induced cell death. Proc Natl Acad Sci USA 94:3309-3313.

Ellis RE, Yuan J, Horvitz R (1991) Mechanisms and functions of cell death. Annu Rev Cell Biol 7:663-698.

Farlie A, Dringen R, Rees SM, Kannourakis G, Bernard O (1995) Transgene expression can protect neurons against development and induced cell death. Proc Natl Acad Sci USA 92:4397-4401.

Garcia I, Martinou I, Tsujimoto Y, Martinou J-C (1992) Prevention of programmed cell death of sympathetic neurons by $b c l-2$ protooncogene. Science 258:302-304.

Garcia-Valenzuela E, Gorczyca W, Darzynkiewicz Z, Sharma SC (1994) Apoptosis in adult retinal ganglion cells after axotomy. J Neurobiol 25:431-438.

Gavrieli Y, Sherman Y, Ben-Sasson SA (1992) Identification of programmed cell death in situ via specific labeling of nuclear DNA fragmentation. J Cell Biol 119:493-501.

Hockenbery DM, Oltai Z, Yin X-M, Milliman C, Korsmeyer SJ (1993) Bcl-2 functions in an antioxidant pathway to prevent apoptosis. Cell 75:241-251.

Horsburgh GM, Sefton AJ (1987) Cellular degeneration and synaptogenesis in the developing retina of the rat. J Comp Neurol 263:553-566.

Hume DA, Perry VH, Gordon S (1983) Immunohistochemical localization of a macrophage-specific antigen in developing mouse retina: phagocytosis of dying neurons and differentiation of microglial cells to form a regular array in the plexiform layers. J Cell Biol 97:253-257.

Huxlin KR, Dreher B, Schulz M, Jervie Sefton A, Bennett MR (1995) Effect of collicular proteoglycan on the survival of adult rat retinal ganglion cells following axotomy. Eur J Neurosci 7:96-107.

Johnson EM, Deckwerth TL (1993) Molecular mechanisms of developmental neuronal death. Annu Rev Neurosci 16:31-46.

Johnson JE, Barde Y-A, Schwab M, Thoenen H (1986) Brain-derived neurotrophic factor supports the survival of cultured rat retinal ganglion cells. J Neurosci 6:3031-3038.
Korsmeyer SJ (1995) Regulators of cell death. Trends Genet 11:101-105. Maffei L, Carmignoto G, Perry VH, Candeo P, Ferrari G (1990) Schwann cells promote the survival of rat retinal ganglion cells after optic nerve section. Proc Natl Acad Sci USA 87:1855-1859.

Mah SP, Zhong LT, Liu Y, Roghani A, Edwards RH, Bredesen DE (1993) The protooncogene bcl-2 inhibits apoptosis in PC12 cells. J Neurochem 60:1183-1186.

Mansour-Robaey S, Clarke DB, Wang Y-C, Bray GM, Aguayo AJ (1994) Effects of ocular injury and administration of brain-derived neurotrophic factor on survival and regrowth of axotomized retinal ganglion cells. Proc Natl Acad Sci USA 91:1632-1636.

Martinou J-C, Dubois-Dauphin M, Staple J, Rodriguez I, Frankowski H, Missoten M, Albertini P, Talabot D, Catsicas S, Pietra C, Huarte J (1994) Overexpression of Bcl-2 in transgenic mice protects neurons from naturally occurring cell death and experimental ischemia. Neuron 13:1017-1030.

Merry DE, Veis DJ, Hickey WF, Korsmeyer SJ (1994) bcl-2 protein expression is widespread in the developing nervous system and retained in the adult PNS. Development 120:301-311.

Mey J, Thanos S (1993) Intravitreal injections of neurotrophic factors support the survival of axotomized retinal ganglion cells in adult rats in vivo. Brain Res 602:304-317.

Miller NM, Oberdorfer M (1981) Neuronal and neuroglial responses following retinal lesions in neonatal rats. J Comp Neurol 202:493-504.

Oppenheim RW (1991) Cell death during development of the nervous system. Annu Rev Neurosci 14:453-501.

Oppenheim RW, Prevette D, Tytell M, Homma S (1990) Naturally occurring and induced neuronal death in the chick embryo in vivo requires protein and RNA synthesis: evidence for the role of cell death genes. Dev Biol 138:104-113.

Osborne BS, Schwartz LM (1994) Essential genes that regulate apoptosis. Trends Cell Biol 4:394-398.

Perry VH (1981) Evidence for an amacrine cell system in the ganglion cell layer of the rat retina. Neuroscience 6:931-944.

Perry VH, Henderson Z, Linden R (1983) Postnatal changes in retinal ganglion cells and optic axon populations in the pigmented rat. J Comp Neurol 219:3546-3568.

Porciatti V, Pizzorusso T, Martinou J-C, Maffei L (1995) Visual responses of axotomized retinal ganglion cells are preserved in transgenic mice overexpressing bcl-2. Soc Neurosci Abstr 21:610.18.

Rabacchi SA, Bonfanti L, Liu X-H, Maffei L (1994a) Apoptotic cell death induced by optic nerve lesion in the neonatal rat. J Neurosci 14:5292-5301.

Rabacchi SA, Ensini M, Bonfanti L, Gravina A, Maffei L (1994b) Nerve growth factor reduces apoptosis of axotomized retinal ganglion cells in the neonatal rat. Neuroscience 63:969-973.

Raff MC (1992) Social controls on cell survival and cell death. Nature 356:397-400.

Thanos S, Mey J, Wild M (1993) Treatment of the adult retina with microglia-suppressing factors retards axotomy-induced neuronal degradation and enhances axonal regeneration in vivo and in vitro. J Neurosci 13:455-466.

Vidal-Sanz M, Bray GM, Villegas-Peres MP, Thanos S, Aguayo AJ (1987) Axonal regeneration and synapse formation in the superior colliculus by retinal ganglion cells in the adult rats. J Neurosci 7:2894-2909.

Weibel D, Cadelli D, Schwab ME (1994) Regeneration of lesioned rat optic nerve fibers is improved after neutralization of myelin-associated neurite growth inhibitors. Brain Res 642:259-266.

Williams MA, Piñon LGP, Linden R, Pinto LH (1990) The pearl mutation accelerates the schedule of natural cell death in the early post-natal retina. Exp Brain Res 82:393-400.

Wood KA, Dipasquale B, Youle RJ (1993) In situ labeling of granule cells for apoptosis-associated DNA fragmentation reveals different mechanisms of cell loss in developing cerebellum. Neuron 11:621-632.

Young RW (1984) Cell death during differentiation of the retina in the mouse. J Comp Neurol 229:362-373. 